\title{
Determinação da altura de chassi em ordem de marcha: cálculo teórico para altura de degrau/plataforma
}

\author{
Eng. Fabiano Monteiro Niehues de Farias \\ Prof. Dr. Jorge Luiz Erthal \\ Universidade Tecnológica Federal do Paraná - UTFPR \\ Universidade Federal do Paraná - UFPR \\ Emails: fabiano.farias@gmail.com, Jorge.erthal@ufpr.br
}

\section{RESUMO:}

Para a fabricação de um ônibus é necessário uma boa interface entre o chassi e carroceria. Um item muito importante deste acoplamento é a determinação de sua altura em relação ao solo. Esta altura é determinada por norma e ocasionalmente restringida em licitações. Devido a diversas variações de chassis e carrocerias no mercado se faz necessário um estudo para garantir a altura do conjunto ao solo a fim de se ter o veículo completo em concordância com a legislação e requisitos do cliente. Uma maneira de determinar esta altura é encarroçando um chassi, tirando as medidas e, finalmente, confirmando se estão dentro das tolerâncias permitidas. Esta opção se torna inviável pelo custo envolvido. Outra opção, antecedendo o projeto da estrutura da carroceria, é carregar o chassi com a carga aproximada e bem distribuída da carroceria completa e medir os valores de altura do chassi. Neste caso tem-se valores mais próximos do conjunto para determinar as dimensões finais do projeto, mas ainda dispendiosos, tanto em tempo quanto em dinheiro. Uma terceira opção, objetivo deste trabalho, é a determinação teórica da altura do chassi utilizando dados reais e de desenhos previamente disponibilizadas pelos fabricantes de chassis e pneus. O processo tem boa aproximação, baixo custo, mas são necessários alguns cuidados prévios, que são imprescindíveis para um bom resultado.

\section{INTRODUÇÃO}

Por regulamentação, um dos principais requisitos no projeto de chassis para ônibus é da altura do veículo em relação ao solo. Esta altura pode ser definida separadamente para o para-choque, saias laterais ou para os degraus. Demais componentes do chassi próximos ao solo, como motor e radiador, são em geral influenciados por tais dimensões.

O controle da interface chassi-carroceria é relativamente complexo, devido à variedade de modelos construídos em função da exigência de mercado, melhoria da qualidade, diminuição de custo, troca de fornecedor ou de novos projetos. Além disso, e não menos importante, temos solicitações especificas do cliente final e os requisitos legais do país em questão.

As variáveis técnicas do chassi e carroceria envolvidas dependem da deformação dos pneus e molas devido à carga e ao acoplamento da carroceria no chassi. Num projeto novo, tais influências são de grande importância por não se ter o produto na sua forma final. 
Todo chassi deve ser projetado de maneira a atender os pré-requisitos de altura garantindo também a diferença para a montagem da estrutura e piso do encarroçamento.

Este trabalho tem como objetivo propor um processo prático e simples baseado na legislação brasileira, para o cálculo da altura do chassi carregado para a condição de ordem de marcha, que possa ser aplicado em qualquer especificação de chassi. O cálculo da altura é efetuado durante o projeto e antes da produção do veículo completo, a fim de minimizar possíveis retrabalhos e gastos com pós venda.

\section{Análise dos documentos que impactam na altura do veículo completo}

Os documentos a seguir influenciam diretamente no projeto de um veículo completo para a determinação da altura dos degraus: Resoluções, Normas, Licitações, Manual Standard e desenhos.

A Norma ABNT NBR15570 [1] contém informações técnicas para a fabricação de veículos urbanos completos para transporte de passageiros. No item 23.5_Degraus das escadas (piso alto) e patamar de embarque (piso baixo), estão detalhadas as dimensões destes componentes. A Figura 1 mostra um corte transversal de um veiculo na região da escada.

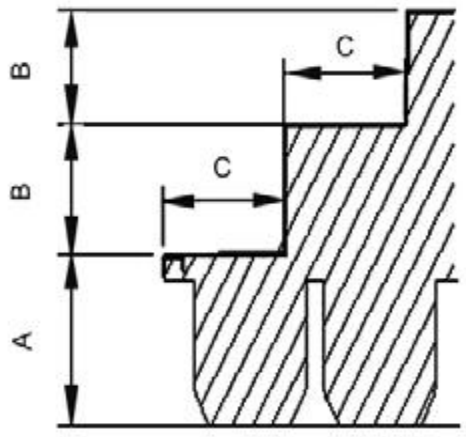

Figura 1. Corte transversal de um veículo mostrando a altura dos degraus das escadas [1].

Para veículos rodoviários, além de alguns itens da NBR 15570 [1] deve ser considerado a Norma Complementar DER 147/85 [2], onde no Artigo 22 - parágrafo $1^{\circ}$ menciona a altura máxima permitida para o primeiro degrau da escada de acesso, medida perpendicularmente ao plano de rolamento do veículo.

Para a inspeção da altura, o veículo deve estar em ordem de marcha, condição descrita na Resolução CONAMA $n^{\circ} 15 / 85$ [3], em que o veículo deve estar completo, inclusive com fluídos e motorista, exceto passageiros.

Já as licitações são baseadas nas normas e resoluções, mas diversos detalhes inclusive tolerâncias são modificadas ou adaptadas pelo órgão gestor do município da licitação, na Tabela 1 tem-se um comparativo das medidas de degraus da Norma ABNT [1] e da URBS [4].

Tabela 1: Comparativo entre NBR [1] e URBS [4]

\begin{tabular}{c|c|c} 
& NBR 15570 [1] & URBS [4], Curitiba \\
\hline Modelo & Suspensão metálica & Comum suspensão metálica \\
\hline A [mm] & 450 & 450 \\
\hline B[mm] & 300 & 300 \\
\hline A+B+B[mm] & 1050 & 1050 \\
\hline Tolerância admitida & $10 \%$ & Alturas máximas, sem tolerância. \\
\hline
\end{tabular}


Esta tabela mostra o detalhe de que a URBS [4] não aceita a tolerância acima do nominal, restringindo a altura máxima dos degraus.

O raio estático (Rs) é o raio do pneu calibrado na pressão máxima e em carga nominal medido do centro da roda ao ponto de apoio do pneu. O Manual standard ETRTO (The European Tire and Rim Technical Organization) [5] padroniza o cálculo do Rs através de tabelas pré-determinadas e das medidas dos pneus. Por isso este raio é um dado teórico.

Em alguns desenhos de chassi é informado o Rs conforme a ETRTO [5]. Para o campo esta informação pode gerar confusão com o raio real final dos pneus dianteiros e traseiros e, consequentemente na altura final da longarina ao solo, mas para a manutenção de desenhos é pratica devido à variedade de marcas e modelos de pneus disponíveis no mercado. O controle e custo para a atualização destes desenhos seriam um desperdício se a informação do Rs fosse informado para cada pneu em produção do chassi.

Para cada fabricante e modelo de pneu o Rs real pode variar devido às alturas de bandas, tipo de borracha e outros detalhes da construção de um pneu.

\section{Processo de aquisição de dados}

A determinação da altura da longarina do chassi depende de duas medidas:

- Raio do pneu, do centro da roda ao solo, com a pressão de calibragem correta para a aplicação;

- Altura entre o centro da roda e o topo da longarina.

2.1 Raio do pneu

Para a obtenção do raio do pneu num veículo completo, deve ser feita uma planilha mostrando o raio do pneu pela carga. Os dados de entrada desta tabela são obtidos em um chassi físico e nos desenhos técnicos dos fabricantes de chassis (desenho de oferta).

Em um chassi físico com seu peso conhecido por eixo, devem ser calibrados os pneus para a pressão de aplicação e medido o raio dos mesmos no eixo dianteiro e traseiro. Estes são os dados da primeira linha da planilha.

Os dados da ultima linha da planilha são o raio estático, mas para a pressão de aplicação e a carga máxima do pneu. O raio estático e carga máxima do pneu podem ser obtidos com o fabricante dos pneus, mas para a pressão máxima do mesmo. Então, um cuidado deve ser tomado nesta hora, deve ser feito um teste de carregamento no chassi considerando a carga máxima por pneu no eixo dianteiro para a obtenção do novo raio estático, mas na pressão de aplicação. Medir o raio dos pneus.

Com estes dados pode ser montada a planilha para a variação do raio pela carga para o eixo dianteiro e traseiro. A variação do raio e da carga na planilha pode ser linear.

2.2 Altura entre o centro da roda e o topo da longarina

Para os chassis com suspensão pneumática a altura do centro da roda ao topo da longarina deve ser obtida no desenho do chassi e para chassis com suspensão metálica deve ser feita 
uma planilha com os valores disponíveis também nos desenhos de chassis. Novamente pode ser feita uma variação linear.

Durante a fase de projeto do encarroçamento o peso da carroceria pode ser estimado.

Somado o peso da carroceria e do chassi, ambos considerados em ordem de marcha, o valor da altura da longarina pode ser conhecida nas planilhas, bastando somar o raio à altura do centro da roda ao topo da longarina.

Com estes valores o projeto da estrutura do piso pode ser ajustado para que a altura dos degraus atenda as especificações finais do veiculo completo.

\section{APRESENTAÇÃO E ANALISE DOS RESULTADOS}

Seguindo o processo descrito anteriormente, apresenta-se a seguir um exemplo aplicado num chassi e posteriormente comparado com um veiculo completo com o chassi da mesma especificação.

3.1 Dados técnicos do chassi

A Tabela 2 apresenta a especificação simplificada do chassi utilizado. A informação do peso do chassi por eixo pode ser obtida com o fabricante do mesmo ou numa balança de carga.

Tabela 2: Dados técnicos do chassi.

\begin{tabular}{|c|c|c|}
\hline \multicolumn{2}{|l|}{ Motor } & Dianteiro \\
\hline \multicolumn{2}{|c|}{ Pontos de apoio/Tração } & $4 \times 2$ \\
\hline \multicolumn{2}{|l|}{ Suspensão } & Metálica \\
\hline \multirow{2}{*}{ Peso do chassi } & Eixo dianteiro $[\mathrm{kg}]$ & 2960 \\
\hline & Eixo traseiro $[\mathrm{kg}]$ & 1930 \\
\hline \multirow{2}{*}{ Pneu } & Tamanho & $275 / 80$ R22,5 \\
\hline & Marca e modelo & Michelin XZU3 \\
\hline
\end{tabular}

As informações da Tabela 3 foram medidas fisicamente no chassi com seus pneus calibrados com $750 \mathrm{kPa}$.

Tabela 3: Raio dos pneus por eixo, pressão de $750 \mathrm{kPa}$.

\begin{tabular}{l|c}
\hline & Raio [mm] \\
\hline Eixo dianteiro & 485 \\
\hline Eixo traseiro & 505 \\
\hline
\end{tabular}

Na Tabela 4 as informações de raio, carga nominal e pressão nominal foram obtidas com o fabricante dos pneus [6].

Tabela 4: Dados técnicos dos pneus do chassi $[5,6]$.

\begin{tabular}{l|l|c}
\hline \multirow{3}{*}{ Pneu } & Tamanho & $275 / 80 \mathrm{R} 22,5$ \\
\cline { 2 - 3 } & Marca e modelo & Michelin XZU3 \\
\cline { 2 - 3 } & Rs, raio estático, ETRTO [5] [mm] & 479 \\
\cline { 2 - 3 } & Carga nominal [kg] & 3159 \\
\cline { 2 - 3 } & Pressão nominal [kPa] & 850 \\
\hline
\end{tabular}


3.2 Levantamento da variação do raio do pneu pela pressão de calibragem

A Tabela 5 apresenta a variação do raio do pneu pela pressão. Este gráfico foi obtido num teste fisco realizado no chassi de referencia, efetuando um carregamento com a carga nominal no eixo dianteiro e variando a pressão dos pneus. Uma opção para não efetuar este teste de carregamento é entrar em contato com o fabricante do pneu e solicitar os valores.

Tabela 5: Variação do raio do pneu pela pressão:

\begin{tabular}{c|c}
\hline Pressão $[\mathrm{kPa}]$ & Raio do pneu $[\mathrm{mm}]$ \\
\hline 850 & 479 \\
\hline 750 & 473 \\
\hline 650 & 467 \\
\hline
\end{tabular}

3.3 Cálculo da deformação do pneu:

Os dados a seguir são inseridos na Tabela 6 para obtenção futura do raio pela carga do veiculo completo:

- Primeira linha: Peso do chassi na Tabela 2 com o raio medido na Tabela 3;

- Última linha: Carga nominal do pneu na Tabela 4 com o raio físico da Tabela 5.

Tabela 6: Variação do raio dos pneus pela carga no eixo dianteiro e traseiro.

\begin{tabular}{c|c}
\hline \multicolumn{2}{|c}{ Eixo dianteiro, dois pneus. } \\
\hline Peso por eixo & Raio do pneu \\
\hline 2960 & 485 \\
\hline 3240 & 484 \\
\hline 3520 & 483 \\
\hline 3800 & 482 \\
\hline 4080 & 481 \\
\hline 4360 & 480 \\
\hline 4640 & 479 \\
\hline 4920 & 478 \\
\hline 5200 & 477 \\
\hline 5480 & 476 \\
\hline 5760 & 475 \\
\hline 6040 & 474 \\
\hline 6318 & 473 \\
\hline
\end{tabular}

Eixo traseiro, quatro pneus.

\begin{tabular}{c|c}
\hline Peso por eixo & Raio do pneu \\
\hline 1930 & 505 \\
\hline 2822 & 502 \\
\hline 3714 & 499 \\
\hline 4606 & 497 \\
\hline 5498 & 494 \\
\hline 6390 & 491 \\
\hline 7282 & 489 \\
\hline 8174 & 486 \\
\hline 9066 & 483 \\
\hline 9958 & 481 \\
\hline 10850 & 478 \\
\hline 11742 & 475 \\
\hline 12636 & 473 \\
\hline
\end{tabular}

A primeira linha da Tabela 6 tem os valores medidos no chassi físico, com o peso do mesmo por eixo (dianteiro e traseiro) e a ultima linha tem o peso nominal admitido pelo conjunto de pneus por eixo e o raio do pneu para esta carga.

3.4 Cálculo da deformação da mola

As alturas A e B na Figura 2 e Tabela 7 são referentes à altura entre o centro da roda e o topo da longarina para o eixo dianteiro e traseiro respectivamente. Estas informações estão disponíveis nos desenho de chassi dos fabricantes. 


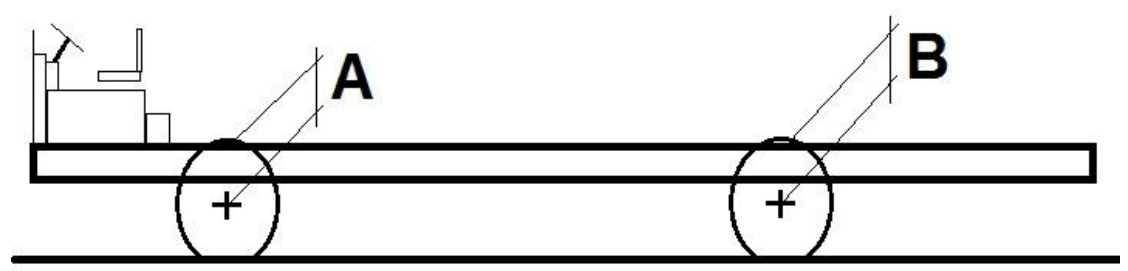

Figura 2: Visualização das cotas A e B.

Tabela 7: Deflexão das molas dianteira e traseira pela carga.

\begin{tabular}{c|c}
\hline Carga $[\mathrm{kg}]$ & $\mathrm{A}[\mathrm{mm}]$ \\
\hline 5000 & 435 \\
\hline 6500 & 409 \\
\hline
\end{tabular}

\begin{tabular}{c|c}
\hline Carga $[\mathrm{kg}]$ & $\mathrm{B}[\mathrm{kg}]$ \\
\hline 5000 & 455 \\
\hline 10800 & 415 \\
\hline
\end{tabular}

Interpolando os valores da Tabela 7 numa variação linear, tem-se a Tabela 8 a seguir:

Tabela 8: Deflexão das molas dianteira e traseira pela carga com variação linear.

\begin{tabular}{c|c}
\hline Peso por eixo $[\mathrm{kg}]$ & A \\
\hline 5000 & 435 \\
\hline 5075 & 433,7 \\
\hline 5150 & 432,4 \\
\hline 5225 & 431,1 \\
\hline 5300 & 429,8 \\
\hline 5375 & 428,5 \\
\hline 5450 & 427,2 \\
\hline 5525 & 425,9 \\
\hline 5600 & 424,6 \\
\hline 5675 & 423,3 \\
\hline 5750 & 422 \\
\hline 8825 & 420,7 \\
\hline 5900 & 419,4 \\
\hline 5975 & 418,1 \\
\hline 6050 & 416,8 \\
\hline 6125 & 415,5 \\
\hline 6200 & 414,2 \\
\hline 6275 & 412,9 \\
\hline 6350 & 411,6 \\
\hline 6425 & 410,3 \\
\hline 6500 & 409 \\
\hline &
\end{tabular}

\begin{tabular}{c|c}
\hline Peso por eixo $[\mathrm{Kg}]$ & $\mathrm{B}$ \\
\hline 5000 & 455 \\
\hline 5290 & 453 \\
\hline 5580 & 451 \\
\hline 5870 & 449 \\
\hline 6160 & 447 \\
\hline 6450 & 445 \\
\hline 6740 & 443 \\
\hline 7030 & 441 \\
\hline 7320 & 439 \\
\hline 7610 & 437 \\
\hline 7900 & 435 \\
\hline 8190 & 433 \\
\hline 8480 & 431 \\
\hline 8770 & 429 \\
\hline 9060 & 427 \\
\hline 9350 & 425 \\
\hline 9640 & 423 \\
\hline 9930 & 421 \\
\hline 10220 & 419 \\
\hline 10510 & 417 \\
\hline 10800 & 415 \\
\hline &
\end{tabular}

3.5 Comparativo entre os cálculos teoricos e um veículo completo fisico

Para verificar a eficácia dos dados acima efetuou-se um comparativo das Tabelas 6 e 8 com um veículo completo físico, Tabela 9, sobre um chassi com as mesmas especificações da Tabela 2. 
Tabela 9: Dados técnicos do veículo completo.

\begin{tabular}{l|l|c}
\hline Modelo & Rodoviário \\
\hline \multirow{2}{*}{ Peso do veículo em ordem de marcha $[\mathrm{kg}]$} & Eixo dianteiro & 5620 \\
\cline { 2 - 3 } & Eixo traseiro & 5700 \\
\hline \multirow{2}{*}{ Raio dos pneus [mm] } & Eixo dianteiro & 475 \\
\cline { 2 - 3 } & Eixo traseiro & 490 \\
\hline \multirow{2}{*}{ Altura do topo da longarina ao solo $[\mathrm{mm}]$} & Eixo dianteiro & 900 \\
\cline { 2 - 3 } & Eixo traseiro & 945 \\
\hline \multicolumn{2}{|l}{ Pressão do pneu na aplicação do veículo $[\mathrm{kPa}]$} & 750 \\
\hline
\end{tabular}

\subsubsection{Comparativo dos raios dos pneus}

A Tabela 10 compara o raio real medido no veículo com o raio obtido teoricamente.

Tabela 10: Comparativo dos raios reais e teóricos.

\begin{tabular}{l|c|c|c}
\hline & $\begin{array}{c}\text { Tabela 9, valor real } \\
\text { Raio do pneu }[\mathrm{mm}]\end{array}$ & $\begin{array}{c}\text { Tabela 6, valor teórico } \\
\text { Raio do pneu }[\mathrm{mm}]\end{array}$ & $\begin{array}{c}\text { Diferença } \\
{[\mathrm{mm}]}\end{array}$ \\
\hline Eixo dianteiro & 475 & 475 & 0 \\
\hline Eixo traseiro & 490 & 492 & -2 \\
\hline
\end{tabular}

Pode-se notar uma diferença para o eixo de tração de $2 \mathrm{~mm}$. Este erro é pequeno e aceitável.

\subsubsection{Comparativo das alturas da longarina ao solo}

A Tabela 11 compara a altura da longarina ao solo, real e teórica.

Tabela 11: Comparativo dos valores teóricos e reais:

\begin{tabular}{l|c|c|c}
\hline & Tabela 9 $[\mathrm{mm}]$ & Tabelas 6 e $8[\mathrm{~mm}]$ & Diferença $[\mathrm{mm}]$ \\
\hline Eixo dianteiro & 900 & $475+424=899$ & 1 \\
\hline Eixo traseiro & 945 & $492+450=942$ & 3 \\
\hline
\end{tabular}

O maior erro encontrado para a altura da longarina é de $3 \mathrm{~mm}$. Este erro é satisfatório se comparado à tolerância de 10\% admitida na NBR15570 [1] da altura do primeiro degrau ao solo de $450 \mathrm{~mm}$. Então para o projeto da estrutura do piso e escadas e as possíveis variações de processo de solda e montagem dos componentes tem-se aproximadamente $42 \mathrm{~mm}$ da tolerância sobrando.

De maneira geral, erros para a predição da altura da longarina ao solo de até $10 \mathrm{~mm}$ são muito bem aceitas pelos encarroçadores do Brasil. Então a aplicação do método descrito é factível.

\section{CONCLUSÃO}

O processo utilizado para a aquisição de dados é sugerido para a obtenção da altura da longarina ao solo de chassi, pois seus dados de entrada são facilmente obtidos fisicamente e/ou por desenhos disponíveis, oferece uma boa aproximação em comparação aos dados reais finais, tem baixo custo e 
não tem restrição de aplicação, podendo ser utilizado como um recurso para os projetos de um veículo completo em qualquer modelo de chassi e carroceria.

Os resultados obtidos teoricamente são aceitáveis para o produto em questão se comparamos com as tolerâncias admitidas na legislação brasileira.

O único dado que despende maior investimento para sua aquisição é a variação do raio do pneu pela pressão, Tabela 5, a não ser que esta informação esteja disponível pelo fabricante dos pneus. Mas se não estiver, precisa ser feita somente uma vez para cada tamanho de pneu e pode ser generalizada para outras marcas.

Como sugestão, para lotes de chassis, deve ser feito um protótipo para confirmar a proximidade dos valores teóricos do processo com os reais. Com estes valores confrontados pode ser feito um ajuste nas planilhas, caso necessário, dependendo da tolerância exigida.

As tabelas apresentadas valem somente para as especificações presentes no exemplo. Devido à grande variedade de chassis e marcas de pneus e seus modelos, deve-se gerar as tabelas correspondentes, utilizando o processo descrito.

\section{REFERÊNCIAS}

[1] ABNT NBR 15570:2011. Transporte: especificações técnicas para a fabricação de veículos com características urbanas para o transporte coletivo de passageiros. Associação brasileira de normas tecnicas. Rio de Janeiro - RJ, 2011.

[2] BRASIL. Departamento Nacional de Estradas de Rodagem. Norma Complementar DER 147:1985. Estabelece padrões técnicos a serem observados na construção dos veículos, inclusive carrocerias, utilizados nos serviços rodoviários interestaduais de transporte coletivo de passageiros. Diário Oficial da União 12 de abr. de 1985, Seção 1, pag. 6043 - 6051.

[3] BRASIL. CONAMA. Resolução CONAMA 15:1995. Dispõe sobre a nova classificação dos veículos automotores para o controle da emissão veicular de gases, material particulado e evaporativo, e dá outras providências. 13 de dez. de 1995. Publicada no DOU no 249, de 29 de dez. de 1995, Seção 1, pág. 22876-22877.

[4] URBS. Urbanização de Curitiba S/A. Disponível em http://www.urbs.curitiba.pr.gov.br. Acesso em: 02 de Jun. de 2011.

[5] ETRTO. Standards Manual. European Tyre and Rim Technical Organization, 2003. Disponível em http://www.etrto.org. Acesso em: 07 de fev. de 2013.

[6] Michelin. Disponível em http://www.michelin.com.br/home.html. Acesso em: 10 de Dez. de 2013. 